\title{
Heuningbos (Cyclopia spp.) volwasse embrioweef- selkultuur en die effek van peulposisie op saadkleur
}

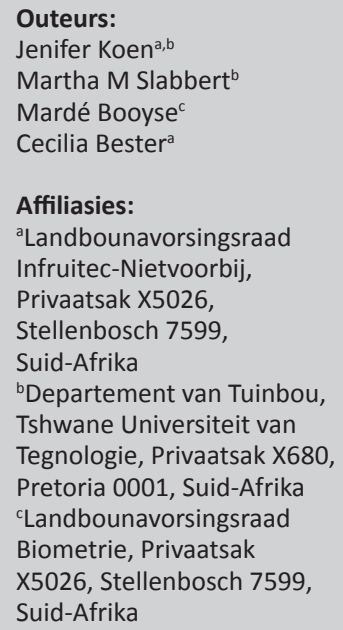

Korresponderende outeur: Jenifer Koen

E-pos:

drjen.greenscience@gmail.com

Datums:

Ontvang: $\quad 05 / 07 / 20$

Aanvaar: $\quad 31 / 05 / 21$

Gepubliseer: 19/08/21

Hoe om hierdie artikel aan te haal:

Jenifer Koen, Martha M Slabbert, Mardé Booyse, Cecilia Bester, Heuningbos (Cyclopia spp.) volwasse embrioweefselkultuur en die effek van peulposisie op saadkleur, SuidAfrikaanse Tydskrif vir Natuurwetenskap en Tegnologie 40(1) (2021). https://doi.org/10.36303/ SATNT.2021.40.1.798

An English copy of this paper is available online at http://www.satnt.ac.za/ index.php/satnt/article/ view/798

\section{Kopiereg:}

(c) 2021. Authors. Licensee: Die SuidAfrikaanse Akademie vir Wetenskap en Kuns. Hierdie werk is onder die Creative Commons Attribution License gelisensieer.
Plante (verskillende genotipes) van Cyclopia spesies word gebruik om Suid-Afrikaanse heuningbostee ('n kruietee produk) te produseer en word tans deur teling vir grootskaalse verbouing verbeter. Saaddimorfisme en dormansie beïnvloed egter die ontkiemingspersentasie negatief. Deur gebruik te maak van volwasse embrioweefselkulture is studies om die ontkiemingspersentasie van saad te verhoog op C. longifolia, C. maculata en C. subternata gedoen. Die effek van stratifikasie op saadontkieming deur geen of 'n kouebehandeling toe te pas, is ook ondersoek. Volwasse embrios is hierna uit sade verwyder en vir 'n 24-uur fotoperiode by $25^{\circ} \mathrm{C} \pm 1^{\circ} \mathrm{C}$ op weefselkultuur gekweek. Die kweek van volwasse embrios deur middel van weefselkulture was suksesvol en het deurlopend meer plante vergeleke met konvensionele saaimetodes gelewer. Studies om die effek wat saadpeulposisie van die moederplant op saadkleur het, is ook gedoen. Volwasse heuningbospeule is vanaf die boonste, middelste en onderste-derdes van die blaarbedekte deel van die heuningbosplante versamel om die aantal groen/intermediêre/bruin sade wat by elke gedeelte geproduseer is, te bepaal. Die verhouding van saaddimorfisme wat by elke gedeelte geproduseer word, kon egter nie deur peulposisie voorspel word nie.

Sleutelwoorde: embrioweefselkultuur, in vitro, kouebehandeling, saaddimorfisme, saaddormansie

Honeybush (Cyclopia spp.) mature embryo culture and the influence of pod position on seed colour: Plants (different genotypes) of Cyclopia, used for production of South African honeybush tea (a herbal tisane product), are being improved through breeding for largescale cultivation, but seed dimorphism and dormancy negatively affect germination percentage. In order to increase the percentage of plants that can be obtained from a batch of seed, mature embryo culture and the influence of pod position on seed colour were investigated for C. longifolia, C. maculata and C. subternata. Mature embryos were excised and cultured in vitro at $25^{\circ} \mathrm{C} \pm 1{ }^{\circ} \mathrm{C}, 24$-hour photoperiod, with and without prior cold treatment. The culture of mature embryos proved to be very successful, consistently resulting in more plantlets than conventional sowing. Mature honeybush pods were also collected from the upper, middle and lower-third foliar portions of honeybush shrubs to determine the number of green/indeterminate/brown seeds produced in each position. However, the ratio of dimorphic seed colours produced could not be predicted by pod position.

Keywords: embryo culture, in vitro, dormancy, cold treatment, seed dimorphism

\section{Inleiding}

Die genus Cyclopia (Familie Fabaceae) is inheems tot die fynbosareas van Suid-Afrika. Daar is 23 erkende spesies binne die genus, almal kruidagtige struike van verskeie groottes. Slegs 'n handvol van hierdie spesies word kommersieel vir "heuningbostee" produksie verbou (Schutte, 1997). Die klein, dog groeiende, heuningbosindustrie voer nagenoeg 390 ton jaarliks uit, met 'n uitvoerwaarde van R 23 miljoen (Departement van Landbou, Bosbou en Visserye, 2016; McGregor, 2017). Kwessies rakende die verbouing en teling van heuningbos het ' $n$ aantal studies geïnisieer wat ter ondersteuning van die industrie aangepak is. Die doel van die hierdie studie was om die aantal plante wat vanaf 'n saadgroep verkry kan word, te verhoog. Probleme rondom saaddormansie, kiemkragtigheid van volwasse saad, asook saadkleur in verhouding tot peulposisie op die plant, is ondersoek. Volwasse embrio-redding vir klein saadgroepe as 'n alternatief vir konvensionele saaimetodes is ook ondersoek.

Direk na afloop van bevrugting, groei en verleng die vrugbeginsels van peulgewasse en word peule gevorm. In die peul ontwikkel die bevrugte kiemselle in klein saadjies (3 tot $5 \mathrm{~mm}$ ). 
Hierdie saadjies het drie geneties-duidelike komponente: die embrio, die endosperm en die saadhuid (Koen et al., 2017). Heuningbosspesies produseer volwasse saad met 'n bruin en/of groen saadhuid, beide kleure word dikwels in dieselfde peul geïnisieer en gevorm (M. Motsa, pers. komm., 2015). 'n Vorige studie het, deur verskillende saadbehandelings toe te pas, bevind dat die verskille in Cyclopia spp se saadkleur ooreenstem met die verskille in die ontkiemingspersentasie (Koen et al., 2017). Resultate van bogenoemde studie het ook getoon dat bruin sade fisies minder noodlottige beskadiging opdoen weens die skarifikasieproses vergeleke met groen sade. Die faktore wat die produksie van verskillende saadkleure van die saadhuid affekteer is tot dusver nog nie vir heuningbos geïdentifiseer nie, maar dit is al bewys dat moederplant omgewingsfaktore dimorfiese saadproduksie van ander spesies affekteer (Cheplick en Sung, 1998; Wang et al., 2008).

Indien bepaal kan word dat die posisie van die peul op die plant'n spesifieke saadkleur tot gevolg kan hê, kan eenderskleurige sade saam geoes word. Sodoende kan die oesproses aangepas word om meer uniforme saadgroepe te verkry. Uitsortering van saad na afloop van die oes kan dan onnodig word. Heuningbossaad het, afhangend van die betrokke spesie, een van beide fisiese of 'n gekombineerde saaddormansie (Baskin en Baskin, 2004; Koen et al., 2017). Hierdie dormansie moet oorkom word alvorens ontkieming kan plaasvind. In vitro uitsnyding en kweek van volwasse heuningbosembrios voordat saadrypwording en uitdroging plaasvind kan fisiese dormansie omseil. Fisiologiese dormansie mag sodoende ook met hulp van hierdie metode omseil word (Debeaujon et al., 2018). Die voorkoms van hierdie dormansies en die gepaardgaande verliese wat voorkom weens konvensionele dormansie-brekende behan- delings, dra by tot die lae persentasie ontkieming van heuningbossaad (Koen, et al., 2017).

Fisiologiese dormansie kan endogeen of eksogeen relatief tot die embrio wees. Endogene dormansie word veroorsaak deur faktore binne die embrio en eksogene dormansie deur faktore soos inhiberende stowwe binne die saadhuid (Baskin en Baskin, 2004). Indien fisiologiese dormansie in heuningbos eksogeen is, sal die verwydering van embrios vanuit hul omliggende weefsel hierdie faktore en die behoefte vir dormansie behandeling soos kouestratifikasie, kan omseil.

Aan die ander kant, indien embrios van gehidreerde sade Fig. 1.a) nie fisiologiese dormansie toon nie, terwyl teenoor embrios wat vanuit gedehidreerde sade verwyder word (Fig. 1.b) wat wel hierdie dormansie toon, mag dit 'n aanduiding wees dat endogene fisiologiese dormansie binnein die embrio tydens of na die uitdroging tydens saad volwassewording ontwikkel.

In heuningbosspesies word fisiologiese dormansie algemeen met 'n sogenaamde "herspruiter" teenoor 'n "hersaaier" veldbrand-oorlewingsstrategie geassosieer (Whitehead en Sutcliffe, 1995; Joubert et al., 2011; Wooldridge et al., 2012; Koen, 2015; Brink et al., 2017). Schutte (1997) beskryf veldbrand-oorlewingsstrategie, of die voorkeur om baie saad te vorm (sogenaamde "hersaaier" spesies) teenoor die produsering van 'n houtagtige ondergrondse wortelstok ("herspruiter" spesies), as 'n handige werktuig om tussen die eienskappe van die heuningbosspesies te onderskei. Hierdie strategie is egter bekend om ook polimorfies in sekere heuningbosspesies te wees (Schutte, 1997; Joubert en Joubert, 2012). Cyclopia longifolia, C. subternata en C. maculata is as hersaaier spesies geklassifiseer (Schutte,

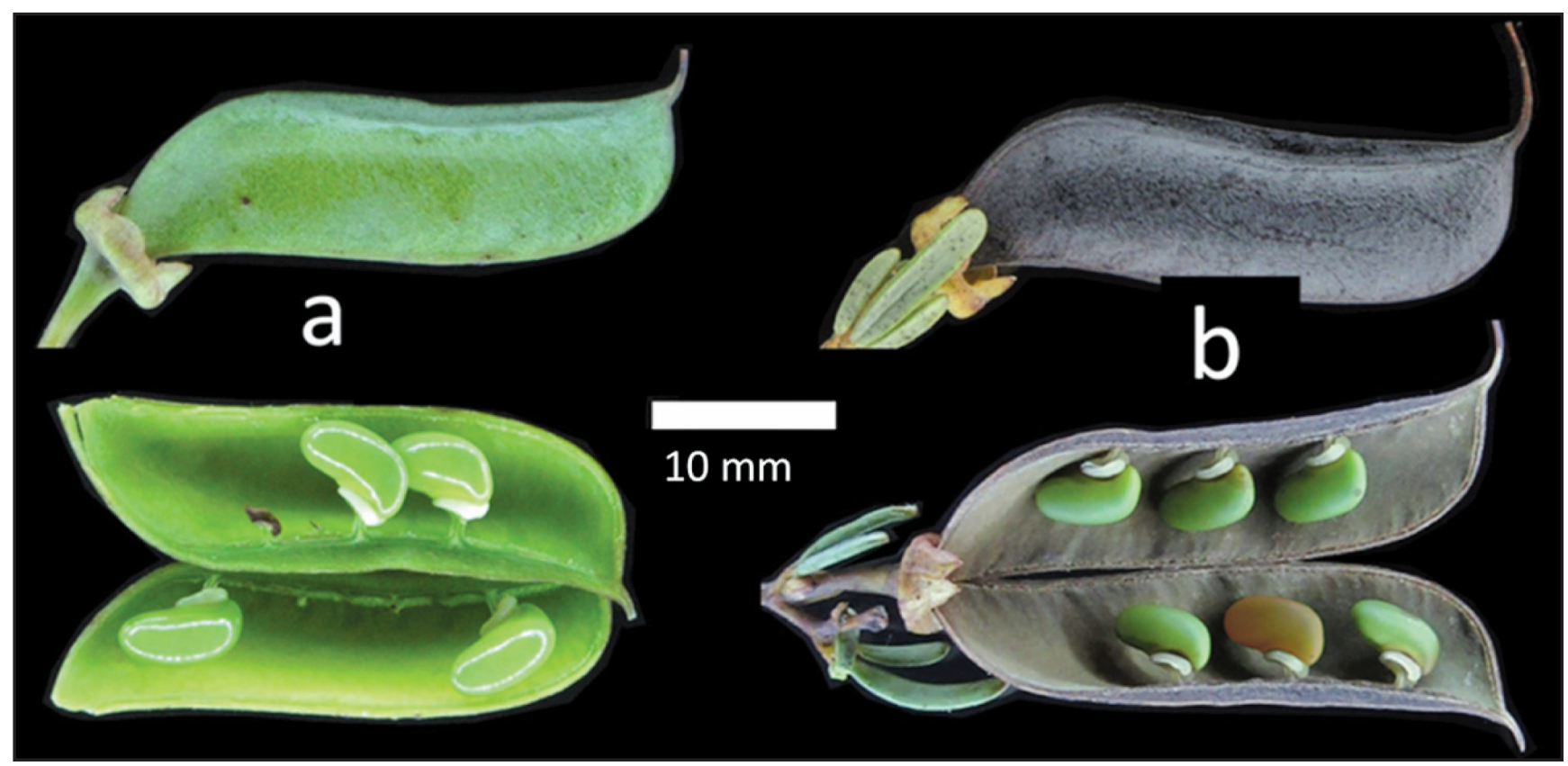

FIGUUR 1: Cyclopia subternata peule, a = voor natuurlike uitdroging (gehidreerde saad); $b$ = na natuurlike uitdroging (gedehidreerde saad) 
1997; Joubert et al., 2011). Joubert en Joubert (2012) het egter aangedui dat $C$. longifolia as ' $n$ hersaaier of herspruiter kan reageer. Daarom het Schutte (1997) doelbewus nie hierdie eienskap van spruitende versus nie-spruitende as klassifikasie in haar kladistiese analise ingesluit nie, omdat dit as 'n "polimorfiese karakter" beskou word wat in sekere populasies teenwoordig en in ander afwesig is.

Alle heuningbosspesies wat voorheen getoets is, het voordeel (in terme van ontkiemingstempo en persentasie) getoon deur 'n voorafgaande koueperiode opgevolg deur waterabsorbsie voor inkubasie of saai (Koen et al., 2017; Whitehead en Sutcliffe, 1995). Fisiologiese dormansie is egter nog nie algemeen vir heuningbosspesies gerapporteer nie.

\section{Materiaal en metodes}

Al die plantmateriaal wat in die eksperimente gebruik was, is versamel van oopbestuiwende heuningbosplante in saadboorde van die Landbounavorsingsraad Nietvoorbij Navorsingsplaas (S 33 54' 23.417" E $18^{\circ}$ 52' 14.196"), naby Stellenbosch in die Weskaap Provinsie van Suid-Afrika. Plantmateriaal is gedurende die tydperk Julie tot Oktober 2017 van drie spesies, i.e., C. longifolia, C. maculata en C. subternata, versamel. Alle chemiekalieë en laboratorium verbruikbare items is van Sigma-Aldrich, Inc. verkry.

\section{Volwasse embrioweefselkultuur}

\section{Versameling van plantmateriaal}

Elke saadgroep was vanaf verskeie individuele kloonplante, afkomstig van dieselfde genotipe, versamel, behalwe vir gedehidreerde saad van C. maculata, wat 'n mengsel van verskeie genotipes was. Beide gehidreerde en gedehidreerde saad is van C. longifolia, kloon LHK8. Vir C. maculata, is gehidreerde saad van kloon MBV4 versamel en gedehidreerde saad van 'n non-spesifieke $C$. maculata mengsel van klone verkry. Vir C. subternata, is beide gehidreerde en gedehidreerde saad van kloon SKB6 versamel. Ten einde embrios van beide saadtipes te verkry, naamlik 1) volwasse gehidreerde, en 2) volwasse gedehidreerde saad, is saadpeule net voor en direk nadat die natuurlike proses van saadvolwassewording plaasgevind het, geoes (Fig. 1.ab). Dit is aanvaar dat gedehidreerde saad binne 'n saadgroep dieselfde vlak van volwassenheid bereik het. Aangesien saad vanaf oopbestuifde bronne van plante verkry is en die aantal dae wat verloop het na bestuiwing onbekend was, kon die volwassenheidsvlak van die gehidreerde saad nie presies vasgestel word nie, en kan dus verskil. Ten einde uniforme resultate tussen die gehidreerde saad te verseker, is saadgroepe gekies vir ooreenstemming met elke spesie. Indien dit bevind is dat die spesifieke embrio volkome volwasse is (op die laaste stadium van ontwikkeling voor uitdroging), is hierdie saadgroep gebruik as 'n visiuele gids en is gehidreerde saad met dieselfde morfologiese eienskappe geselekteer vir daardie spesie vir die res van die eksperiment. Tien embrios is vir elke herhaling gedissekteer, met vier herhalings per behandeling.

\section{Saadbehandeling}

Gedehidreerde saad het 'n skarifikasie en rehidrasie behandeling benodig voor die embrios gedissekteer kon word en is voor die oppervlaksterilisasie afgehandel. Skarifikasie is gedoen deur die saad in gekonsentreerde (95\%) swaelsuur te plaas waarna dit drie keer met water afgespoel is. Suurblootstelling is vir een uur vir C. longifolia, 45 min vir C. maculata en een uur vir C. subternata (Bester en Koen, 2017) toegepas. Die gedehidreerde saad was toegelaat om vir 6 ure in water te week. Geen addisionele behandeling is toegepas nie. Dieselfde sterlisasiemetode is vir beide die gehidreerde en gedehidreede sade se buitenste oppervlakte gevolg. Die saad is onder lopende kraanwater vir 15 minute afgespoel, waarna dit vir vyf minute in 'n $1 \%$ natriumhipochloriedoplossing geweek is. Daarna is die saad drie keer met steriele water afgespoel voordat dit vinning (vir ongeveer een minuut) in etanol gespoel is wat met drie finale afspoelings met gesteriliseerde water opgevolg is. Gehidreerde saad se buitenste oppervlak is egter gesteriliseer direk nadat dit vanuit die peule verwyder is. Embrios van elke saadtipe is onder steriele toestande gedissekteer deur gebruik te maak van 'n laminêre vloeikabinet.

\section{Weefselkultuurmedium}

Embrios is op Murashige en Skoog (1962) basiese medium, Sigma-Aldrich, Inc. produk kode M5524, geplaas. Die basiese medium is voorberei teen halfsterkte en deurgaans in die studie gebruik, i.e., dat 4.3 gram poeier in twee liters water in plaas van een liter water opgelos is. Volgens literatuur word wortelgroei hierdeur gestimuleer (Dewir et al., 2016; Kokotkiewicz et al., 2012; Pratap et al., 2010; Sánchez-Romero et al., 2007; Smith, 2013). Die voorafbereide MS basiese mediummengsel wat beide sout en vitamiene ingesluit het, is saam met plantweefselkultuur$\operatorname{agar}(0.8 \% \mathrm{w} / \mathrm{v})$, sukrose $(1.5 \% \mathrm{w} / \mathrm{v})$ en geaktiveerde houtskoolpoeier $(0.8 \% \mathrm{w} / \mathrm{v})$ voorberei, waarna die mediums se $\mathrm{pH}$ aangepas is na 5.6 voor dit in 'n outoklaaf gesteriliseer is. Medium is in polistireen petribakkies (95 $\mathrm{mm}$ ) gegiet, agt bakkies per medium, ongeveer $30 \mathrm{ml}$ per bakkie. Nadat die embrios gedissekteer en op medium geplaas was, is die bakkies met Parafilm ${ }^{\circledR}$ geseël.

\section{Inkubasie kondisies en dataversameling}

Die helfte van die petribakkies is direk in ' $n$ temperatuur beheerde inkubator teen $25^{\circ} \mathrm{C} \pm 1{ }^{\circ} \mathrm{C}$ met 'n 24-uur fotoperiode en $35 \mu \mathrm{mol} \mathrm{m} \mathrm{m}^{-2} \mathrm{~s}^{-1}$ ligintensiteit geplaas. Die oorblywende petribakkies is in 'n yskas teen $4^{\circ} \mathrm{C}$ in die donker vir twee weke geplaas (koue stratifikasie behandeling), voordat dit in die inkubator geplaas is. Elke petribakkie het 10 embrios bevat en een herhaling verteenwoordig. Vir elke embrio wat direk in die inkubator geplaas is, het dag 7 die eerste observasie dag verteenwoordig. Vir 
embrios wat ' $n$ kouehandeling ontvang het voordat dit in die inkubator geplaas is, was die eerste dag in die inkubator (dag 0) die eerste observasie dag omdat daar verwag was dat sommige van die embrios gedurende die twee weke kouebehandeling reeds kon begin ontkiem het (Koen et al., 2017). Wanneer die gesamentlike wortel en hipokotiellengte $\geq 10 \mathrm{~mm}$ bereik en al die saadlobbe oopgegaan het, was die embrios getel as ontkiem en uit die petribakkie verwyder en in 'n $180 \mathrm{ml}$ kultuurbottel, wat op dieselfde metode met halfsterkte MS basiese medium formule vir voortgesette groei (ongeveer $30 \mathrm{ml}$ per bottel) voorberei is, geplaas.

\section{Positiewe kontrole}

Tweehonderd sade elk van C. longifolia (LHK8), C. maculata (verskeie klone van 2017) en C. subternata (SKB6) is in aparte saailaaie gesaai sodat die sukseskoers tussen embriokulture en konvensionele saaimetode vergelyk kon word. Groeimedium vir saailaaie en suurskarifikasie is volgens die heuningboshandleiding vir saailinge van die Landbounavorsingsraad uitgevoer (Bester en Koen, 2017).

\section{Statistiese Metodes}

'n Volkome ewekansige blokontwerp is as eksperimentele uitleg gebruik. Ses eksperimente (drie spesies met twee saadtipes elk) is gekombineer nadat die variansie van homogenisiteit getoets is (Levene, 1960). Elke eksperiment het uit ' $n$ split-plot bestaan waar medium die hoofplot en stratifikasiebehandeling die subplot was. Die data is as persentasie ontkieming waargeneem en aan gekombineerde analise van variansie onderwerp deur van die General Linear Models Procedure (PROC GLM) van SAS sagteware (Version 9.4; SAS Institute Inc, Cary, USA) gebruik te maak. Shapiro-Wilk toets is uitgevoer op die gestandariseerde residue van die model om normaliteit te verifieer (Shapiro en Wilk, 1965). Fisher's se nie-betekenivolle verskil is teen die 5\% waarskynlikheidsvlak bepaal deur behandelings se gemiddeldes te vergelyk (Ott en Longnecker, 2001). 'n Waarskynlikheidsvlak van minder of gelyk aan $5 \%$ is vir alle toetse as betekenisvol aanvaar.

\section{Effek van peulposisie}

\section{Versameling van plantmateriaal}

Volwasse, toe-peule van oopbestuifde saadboorde is versamel om die effek van peulposisie op saadkleurdimorfisme te bepaal. Vyftien peule is vanaf die onderste, middel en boonste derde van twee spesies en drie heuningbosklone per spesie versamel. Die C. longifolia klone LGR2, LHK23 en LHK35 en die C. maculata klone MBV3, MBV4, MBV10 was gebruik. Vyf peule per herhaling met drie herhalings per kloon was gebruik. Die spesie $C$. subternata kon ongelukkig nie in die studie ingesluit word nie omdat die volwasse peule reeds deur werkers versamel en gemeng was. Nadat die peule uitgedop is, is die saad volgens peulposisie en herhaling gegroepeer terwyl die klone en spesies apart gehou is. Die saad is in drie kleurgroepe verdeel (groen, bruin en intermediêr) en getel.

\section{Statistiese Metodes}

Die eksperimentele uitleg was 'n volkome ewekansige blokontwerp wat bestaan het uit drie herhalings, twee spesies en drie klone per spesie. Die behandelingsuitleg binne 'n spesie was 'n split-split plot met klone as hooffaktor. Die eerste subplotfaktor was die saadposisie (onderste, middel en boonste derde van die plant) en die tweede was die saadkleur (groen, bruin en intermediêr). Die Levene toets het getoon dat daar geen heterogene (nie vergelykbaar) spesie variansies is nie (Levene, 1960). Om laasgenoemde rede is die data aan 'n geweegde gekombineerde analise van variansie onderwerp deur die General Linear Models Procedure (PROC GLM) van SAS sagteware (Version 9.2; SAS Institute Inc, Cary, USA) te gebruik. Die gewigte was die wedersydse variansie van elke spesie (John en Quenouille, 1977). Die Shapiro-Wilk toets is uitgevoer op die gestandariseerde residue van die model om normaliteit te verifieer (Shapiro and Wilk, 1965). Fisher's se nie-betekenivolle verskil is bepaal teen die 5\% waarskynlikheidsvlak deur behandelingsgemiddeldes te vergelyk (Ott en Longnecker, 2001). 'n Waarskynlikheisvlak van minder of gelyk aan $5 \%$ is as betekenivol vir alle betekenisvolle toetse aanvaar.

\section{Resultate \\ Volwasse embrioweefselkultuur}

Resultate van die konvensionele gesaaide saad (positiewe kontrole) was $75 \%$ ontkieming vir C. longifolia, 38\% vir C. maculata en $70 \%$ vir C. subternata (geen figuur beskikbaar).

\section{Spesies}

Klein, maar betekenivolle verskille is gesien in die aantal embrios wat ontwikkel en die wat mikrobiese kontaminasie gekry het (dood) (Ontwikkel: kleinste betekenivolle verskil $(\mathrm{KBV})_{\mathrm{p}=0.05}=4.9$; Dood: $\mathrm{KBV}_{\mathrm{p}=0.05}=5.6$; Fig. 2). Geen betekenivolle verskille is waargeneem in die aantal embrios tussen die drie spesies wat onderontwikkeld gebly het nie. Cyclopia maculata en C. longifolia het die hoogste persentasie embrios wat ontkiem het gehad, maar dit was nie betekenivol verskillend tussen die twee spesies nie. Alhoewel daar geen betekenivolle verskille tussen $C$. subternata en $C$. longifolia was nie, het betekenisvol minder C. subternata embrios in vergelyking met $C$. maculata ontkiem. Die aantal plante wat vanaf embrioweefselkulture verkry is, was met $24 \%$ vir C. longifolia, $56 \%$ vir C. maculata en $18 \%$ vir C. subternata meer as die positiewe kontrole.

\section{Kouebehandeling}

Daar was geen betekenisvolle verskille tussen hoe spesies met of sonder kouebehandeling gereageer het nie en gevolglik is spesies saamgevoeg vir 'n totaal van 120 embrios per behandeling. Betekenivolle verskille is in die aantal embrios wat ontwikkel het, dood is en die wat 


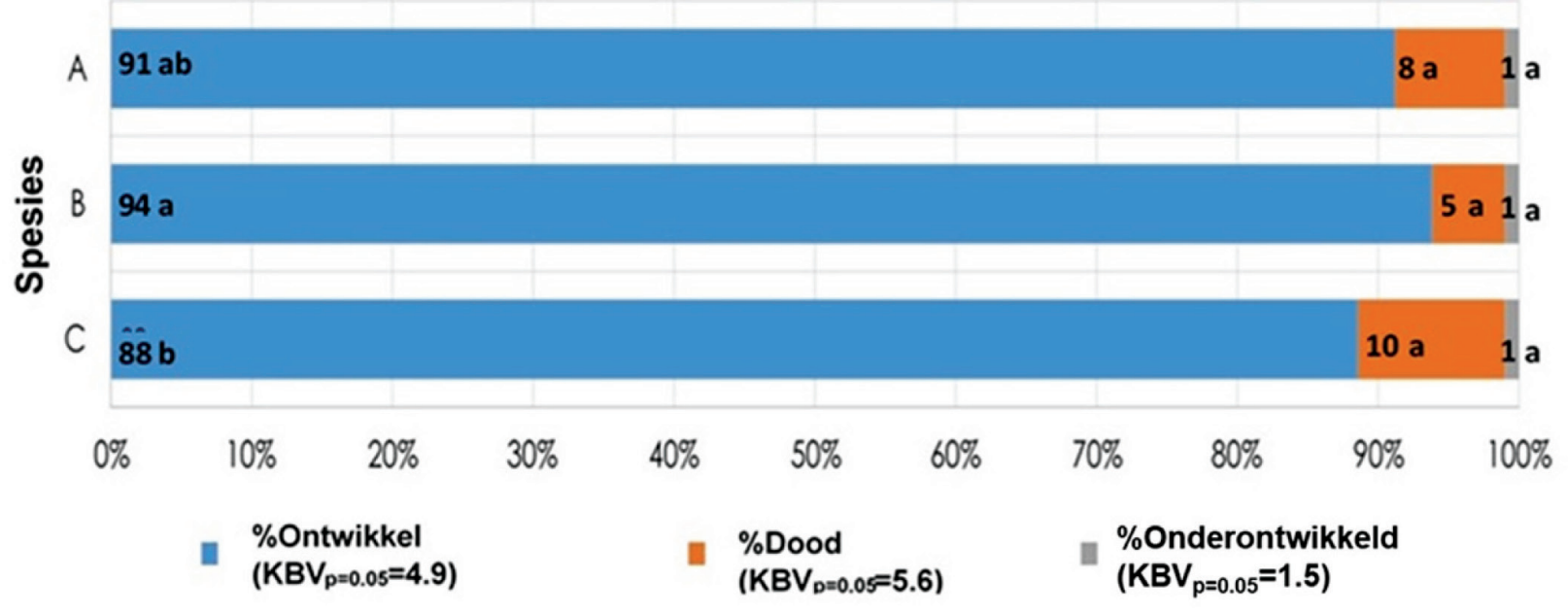

FIGUUR 2: Persentasies van Cyclopia spp. embrios wat ontwikkel het, dood is of onderontwikkeld gebly het, volgens die spesies. A = C. longifolia; $\mathrm{B}=\mathrm{C}$. maculata; $\mathrm{C}$ $=C$. subternata. Gemiddeldes met dieselfde kleur en letter is nie betekenisvol verskillend by $p=0.05$ nie. Waardes afgerond tot die naaste heelgetal.

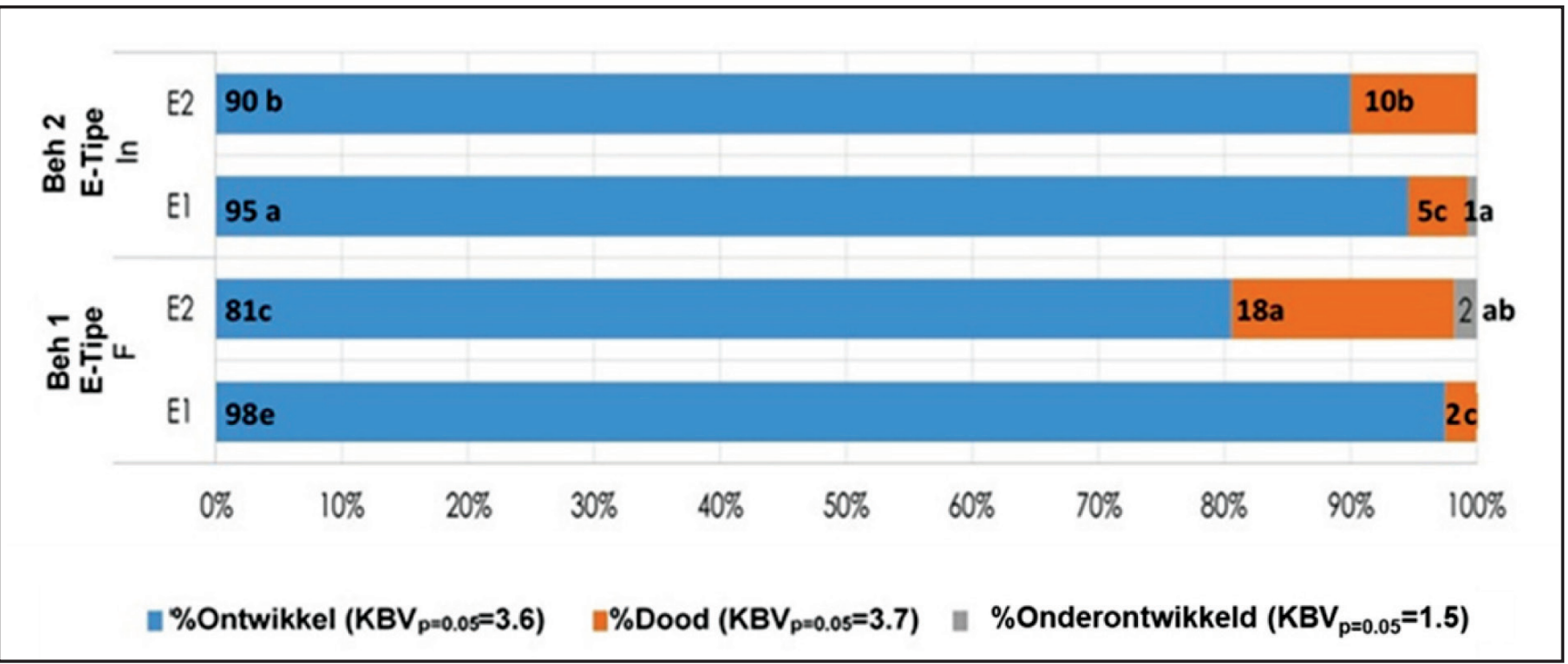

FIGUUR 3: Persentasies van Cyclopia spp. embrios wat ontwikkel het, dood is of onderontwikkeld gebly het volgens die behandeling en embriotipe. Behandeling 1 = koue behandeling; Behandeling 2 = sonder kouebehandeling; E-tipe = embriotipe; $\mathrm{E} 1$ = gehidreerde embrios; E2 = gedehidreerde embrios. Gemiddeldes met dieselfde kleur en letter is nie betekenisvol verskillend by $p=0.05$ nie. Waardes afgerond tot die naaste heelgetal. Nul waardes uitgelaat.

onderontwikkeld gebly het asook in die interaksie tussen behandeling en embrio tipe gevind (Ontwikkel: $\mathrm{KBV}_{\mathrm{p}=0.05}=3.6$; Dood: $\mathrm{KBV}_{\mathrm{p}=0.05}=3.7$; Onderontwikkeld gebly: $\mathrm{KBV}_{\mathrm{p}=0.05}=1.5$ ) (Fig. 3). In beide behandelings is betekenisvolle groter persentasies van ontwikkelde embrios in vergelyking met gedehidreerde embrios gevind. Daar was geen betekenivolle verskille tussen die resultate vir gehidreerde embrios vir beide behandelings nie (Fig. 3) en vir gedehidreerde embrios, het die kouebehandeling betenisvol minder plante in vergelyking met die behandeling sonder koue gehad.

Soos verwag, het 'n aantal embrios (ongeveer 5\%) gedurende die koue stratifikasie behandeling begin ontkiem. Dit is ook waargeneem dat selfs embrios wat nie gedurende die kouebehandeling ontkiem het nie, opmerklik in grootte toegneem het terwyl hulle proporsioneel hul embrioniese verhouding behou het en vining ontwikkel het na verskuiwing na die groeikabinet.

\section{Effek van peulposisie}

Gemiddelde aantal sade versamel vir spesies, peulposisie en saadkleur

Die gemiddelde aantal sade per peul wat per spesie versamel is, betreffende al die faktore, was 11.84 vir $C$. maculata en 6.77 vir C. longifolia. Die spesie C. maculata het betekenisvol meer saad per peul as C. longifolia gevorm ('n verskil van $27 \% ; \mathrm{KBV}_{\mathrm{p}=0.05}=1.03$; Fig. 4). Peulposisie het nie 'n groot effek op op die aantal sade wat gevorm het gehad nie. Die gemiddelde aantal sade per peul versamel, betreffende al die faktore, was 8.54 vir die boonste posisie, 8.15 vir die middel posisie en 7.34 vir die onderste posisie. Peule wat vanaf die boonste posisie geneem is, het meer 

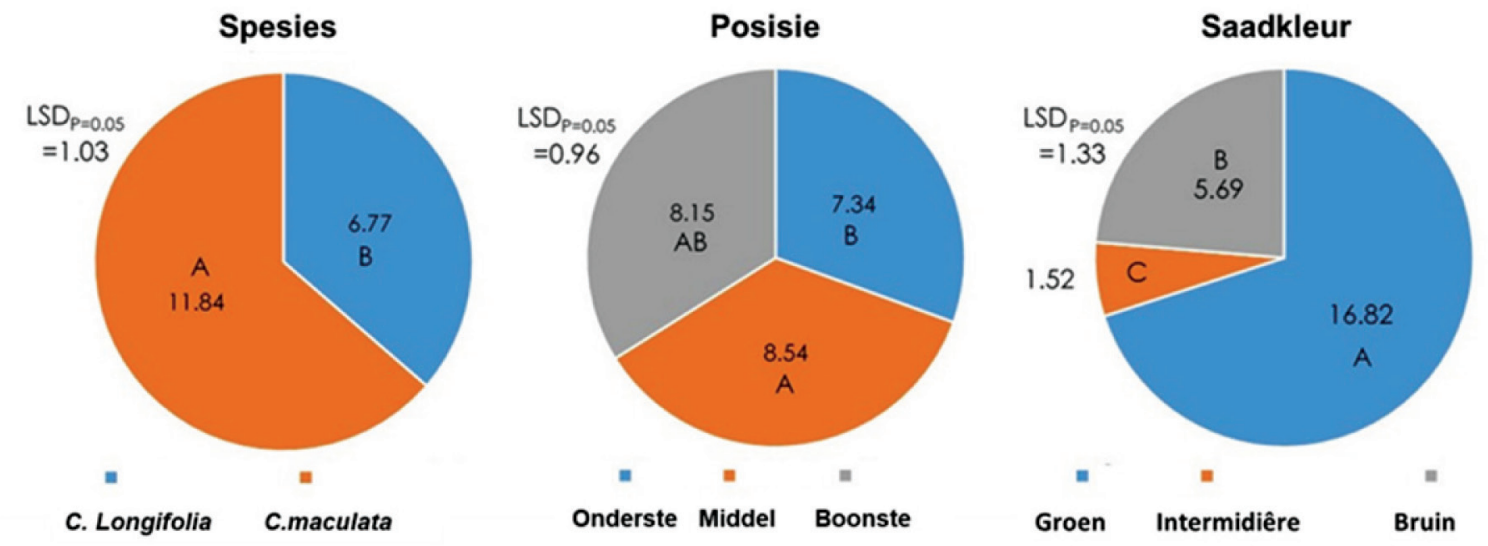

FIGUUR 4: Gemiddelde aantal Cyclopia spp. sade wat vanarsamel is, verwerk vir spesies, posisie en saadkleur onderskeidelik. Gemiddeldes met dieselfde kleur en letter is nie betekenisvol verskillend by $p=0$ nie.

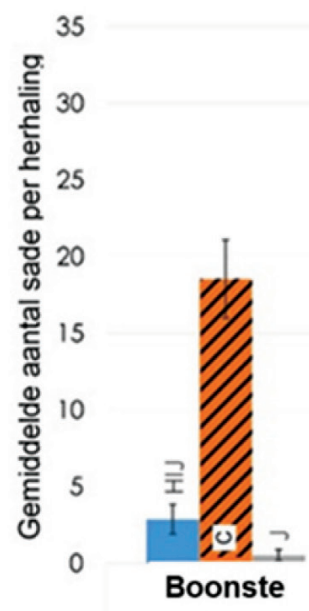

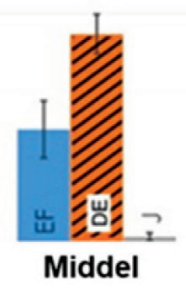

C. Iongifolia

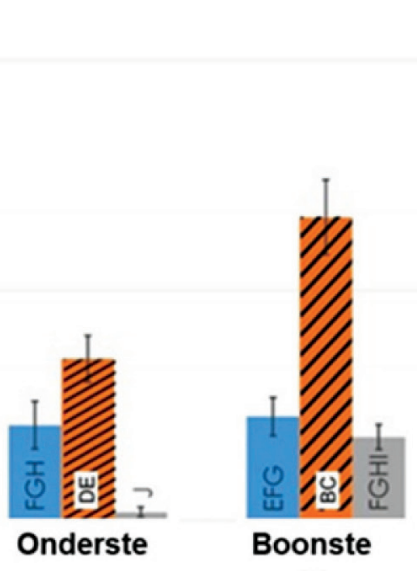

Spesies

- Bruin $=$ Groen " Intermidiêre

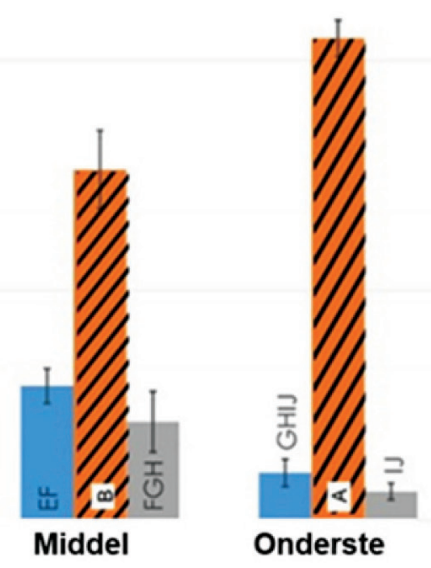

C. maculata

FIGUUR 5: Gemiddelde aantal Cyclopia spp. sade per spesie per herhaling (vyf peule) versamel, saamgevoegde spesie interaksies tussen spesies, peulposisie, en saadkleur. Gemiddeldes met dieselfde letter is nie betekenisvol verskillend by $p=0.05$ nie.

sade as die van laer posisies geproduseer, maar die verskil, alhoewel statisties betekenivol, was klein (3\%; $\mathrm{KBV}_{\mathrm{p}=0.05}=0.96$; Fig. 4). Die gemiddelde aantal sade per saadkleur versamel, betreffende al die faktore, was 16.82 vir groen, 5.69 vir bruin en 1.52 vir intermediêr. Oor die algemeen was betekenisvol meer groen $(70 \%)$ teenoor bruin $(24 \%)$ of intermediêre saad $(6 \%)$ gevorm $\left(\mathrm{KBV}_{\mathrm{p}=0.05}=1.33\right.$; Fig. 4).

\section{Vergelyking van spesies}

Statisties betekenisvolle interaksies was tussen peulposisie, saadkleur, spesies en klone binne spesies waargeneem. Die gemiddeldes vir spesieklone het bewys dat daar meer groen as bruin of intermediêre sade geproduseer word vir alle peulposisies (Fig. 5). Die enigste ander waarskynlike ooreenkoms in die patroon van interaksie vir peulposisie en saadkleur tussen die spesies was 'n geringe neiging vir 'n groter aantal bruin sade wat by die middelste posisie vir beide spesies geproduseer word (Fig. 5).

\section{Vergelyking van klone}

Daar was heelwat variasie in die verhouding van dimorfiese saad wat by die verskillende posisies geproduseer is en is by die klone van beide spesies waargeneem (Fig. 6-7). Daar is geen vaste patroon in saadkleurverspreiding in verhouding tot peulposisie tussen die klone van die spesies waargeneem nie. Die grootse aantal groen sade was vanaf die boonste posisies versamel in twee van die drie klone vir C. longifolia (Fig. 6), en vanaf die onderste posisie vir twee van die drie klone vir C. maculata (Fig. 7). 


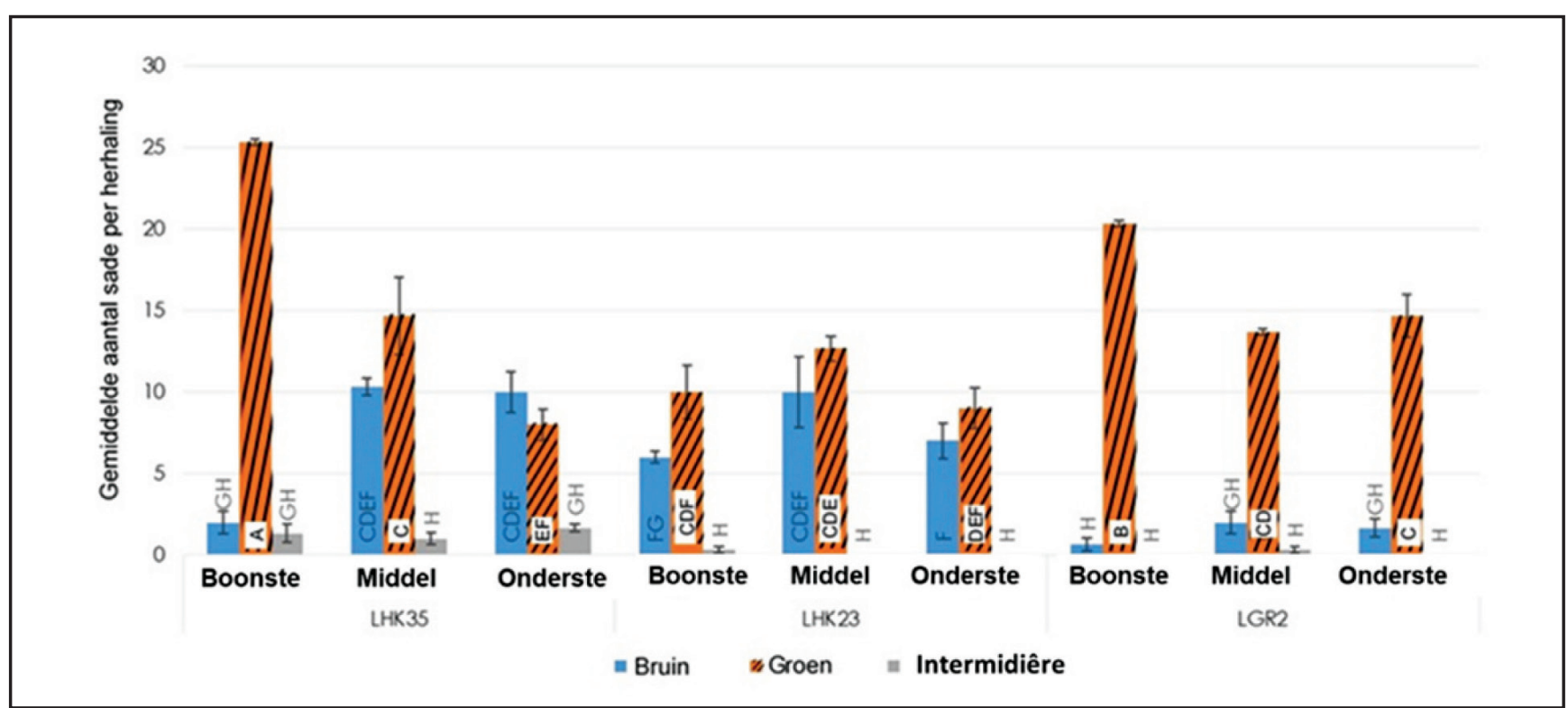

FIGUUR 6: Gemiddelde aantal Cyclopia longifolia sade per kloon per herhaling (vyf peule) versamel, saamgevoegde spesie interaksies tussen klone, peulpossisie en saadkleur. Gemiddeldes met dieselfde letter is nie betekenisvol verskillend by $p=0.05$ nie.

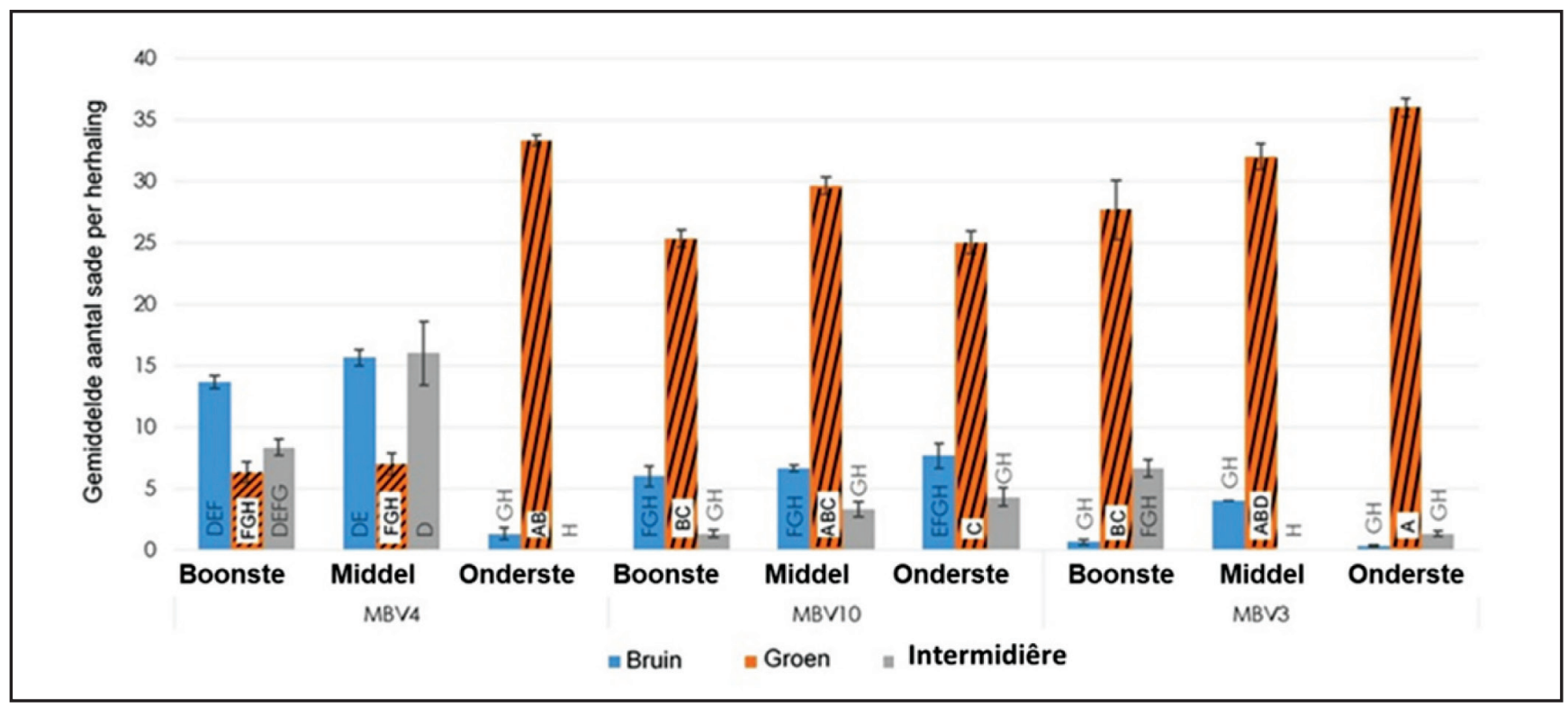

FIGUUR 7: Gemiddelde aantal Cyclopia maculata sade per kloon per herhaling (vyf peule) versamel, saamgevoegde spesie interaksies tussen klone, peulpossisie en saadkleur. Gemiddeldes met dieselfde letter is nie betekenisvol verskillend by $p=0.05$ nie.

\section{Bespreking}

\section{Volwasse embrioweefselkultuur}

\section{Spesies}

Alhoewel C. maculata as 'n saadspesie beskou word (Schutte, 1997), kan die lae persentasie saailinge vanaf konvensionele saaimetodes van C. maculata saad (38\%) waarskynlik aan die teenwooordigheid van 'n mate van fisiologiese saaddormansie in die saadgroep wat getoets was, toegeskryf word. Wanneer die persentasie saailinge vergelyk word met die persentasie plante wat vanaf gedissekteerde C. maculata embrios ontwikkel het (94\% sien Fig. 2), is die verskil tuseen die twee metodes baie duidelik. Dit kan ' $n$ aanduiding van fisiologiese dormansie in heuningbossaad wees wat eksogeen relatief tot die embrio is - m.a.w. deur die saadhuid en/of endospermweefsel veroorsaak. Dit is ook belangrik om te onthou dat slegs een kloon (MBV4) vir die kweek van embrios van gehidreerde saad gebruik was, terwyl verskeie klone van die oesjaar 2017 in die eksperimente vir kweek van embrios van gedehidreerde saad en konvensionele saaimetodes gebruik was. Dit is dus moonlik dat genotipiese variasie tussen $C$. maculata klone 'n effek op die finale resultaat kon gehad het. Tog was die persentasie plante wat in weefselkultuur van die gemengde klone $C$. maculata saadgroep ontwikkel het, nog steeds baie meer as die persentasie saailinge wat vanaf konvensionele saaimetodes nl. die positiewe kontrole, verkry is. In die konvensionele saaimetode eksperiment, is ontkiemingspersentasies vir C. longifolia en $C$. 
subternata relatief hoog, soos wat vir hersaaier spesies verwag kan word (Motsa et al., 2017; Schutte, 1997). Nogtans is die aantal plante wat deur volwasse embrioweefselkultuur verkry is, ook hoër as die aantal saailinge wat vanaf konvensioneleel saaimetodes vir die twee spesies verkry is.

\section{Kouebehandeling}

Geen betekenisvolle verskille is tussen die behandelings waargeneem nie, asook geen interaksies tussen die spesies nie. Dit blyk dat kouestratifikasie van gedissekteerde heuningbos embrios onnodig is, alhoewel dalk nuttig as 'n kondisionerende behandeling, omdat fisiologiese dormansie deur die verwydering van embrios uit hul saadhuid/ endosperm omseil was. Toekomstige studies met ander heuningbosspesies mag hierdie bevindinge bevestig, soos bv. C. intermedia, wat bekend is om fisiologiese dormante saad te produseer (Whitehead en Sutcliffe, 1995).

\section{Effek van saadposisie}

Die doel van die hierdie studie was om te bepaal of saad tydens oes volgens kleur onderskei kan word deur bloot die peule vanaf verskillende hoogtes van die plant te groepeer. Alhoewel betekenivolle statistiese verskille opgemerk is (Fig. 6 en 7), is die effek nie groot genoeg om 'n praktiese verskil aan die probleem om tussen saadkleur te onderskei te maak nie. Genetiese variasie sal moontlik 'n beduidende faktor wees om gedragsverskille in hierdie genus (Cyclopia) van poliploïde spesies te bepaal, maar moederplant-veldomgewing interaksie is ook al met uiteenlopende saadeienskappe in ander spesies gekoppel, en moet daarom in ag geneem word (Carta et al., 2016; Gutterman, 2000; Motsa et al., 2018; Penfield en MacGregor, 2016; Postma en Ågren, 2015; Wulff, 2017). Omgewingsfaktore (nl. plaaslike klimaat) wat 'n effek op saadontwikkeling kan hê, sluit fotoperiode en ligintensiteit, hoogte bo seespieel, water stres, en veral temperatuur in (Carta et al., 2016; Gutterman, 2000; Penfield en MacGregor, 2016). Volgens Penfield en MacGregor (2016), kan selfs geringe verskille in moederplant en/of omgewingsfaktore tot saaddimorfisme aanleiding gee, omdat die saadhuid 'n "hoogs plastiese orgaan" is, m.a.w baie reaktief op omgewingsseine (ongeag of dit deur die moedergenotipe of 'n direkte reaksie op die sigoot is). Onlangse studies op heuningbosspesies het sommige van hierdie raaisels begin ontrafel betreffende die blomstruktuur en stuifmeelkiemkragtigheid, wat ook 'n effek op die interaksies tussen bestuiwing en gevolglik suksesvolle bestuiwing kan hê (Koen et al., 2020a; Koen et al., 2020b). Dit is waarskynlik dat ' $n$ komplekse kombinasie van al die bogenoemde faktore verantwoordelik is vir die hoogs veranderlike verhoudings van dimorfiese saad wat tydens oopbestuiwing van heuningbos onder veldkondisies geproduseer word. Toekomstige studies kan die effek van hierdie interaksies op die verhoudings en verspreiding van bruin en groen saadkleur in heuningbos ondersoek. Tans is daar nog te veel onbeantwoorde vrae om 'n ingeligte voorspelling ten opsigte van die primêre veroorsakende faktore te maak.

\section{Gevolgtrekking}

In die embrioweefselkultuuur eksperiment het in vitro kweking deurgaans hoër persentasies plante as konvensionele saaimetodes gelewer, en mag dit tot'n lewensvatbare alternatief tot ontkieming vir klein saadgroepe aanleiding gee. Saaddormansie is suksesvol deur die verwydering van die saadhuid omseil en dus kouebehandeling (stratifisering) onnodig gemaak. Dit dui daarop dat saaddormansie eksogeen tot die embrio is en verdere studies, word aanbeveel. Die gebruik van gehidreerde saad van volwasse embrioweefselkulture was meer suksesvol as gedehidreerde saad en word aanbeveel. 'n Afhardingsprotokol word nog benodig vir plante wat vanaf embrioweefselkulture verkry is. In hierdie dimorfiese saadstudie is dit bevind dat die verhouding dimorfiese saad wat geproduseer word nie baie deur peulposise geaffekteer word nie. Daarom sal die verkryging van uniforme saadgroepe van 'n eenvormige kleur nie so maklik wees deur bloot die oesmetode aan te pas nie. Die bepalende faktore wat saadhuidkleur in heuningbosspesies beïnvloed, moet nog vasgestel word.

\section{Erkenning}

Hierdie studie was deur die Departement van Wetenskap en Innovasie (DWI) [Kontrak DST/Con 00023/2015] befonds, asook finansiële ondersteuning is verkry vanaf Tegnologie en Menslike Hulpbronne vir Industrie Program (THRIP) [Toekenning TP14072479871], en die tesouriebefondsing aan die Landbounavorsingsraad (LNR) en Tshwane Universiteit van Tegnologie (TUT).

\section{Verwysings}

Baskin, J.M., Baskin, C.C. 2004. A classification system of seed dormancy. Seed Science Research 14(1), 1-16. https://doi.org/10.1079/SSR2003150.

Bester, C., Koen, J. 2017. Manual for propagation of honeybush seedlings and cuttings. 16 pages. Located at: Crop Development Division, Agricultural Research Council, Stellenbosch.

Brink, C., Postma, A., Jacobs, K. 2017. Rhizobial diversity and function in rooibos (Aspalathus linearis) and honeybush (Cyclopia spp.) plants: A review. South African Journal of Botany 110, 80-86. https://doi.org/10.1016/j. sajb.2016.10.025

Carta, A., Probert, R., Puglia, G., Peruzzi, L., Bedini, G. 2016. Local climate explains degree of seed dormancy in Hypericum elodes L. (Hypericaceae). Plant Biology 18, 76-82. https://doi.org/10.1111/plb.12310.

Cheplick, G.P., Sung, L.Y. 1998. Effects of maternal nutrient environment and maturation position on seed heteromorphism, germination, and seedling growth in Triplasis purpurea (Poaceae). International Journal of Plant Science 159(2), 338-350. https://doi.org/10.1086/297555.

Debeaujon, I., Lepiniec, L., Pourcel, L., Routaboul, J-M. 2018. Seed coat development and dormancy. Annual Review of Plant Biology. [accessed October 07 2019]: https://www.researchgate.net/profile/Loic Lepiniec/ publication/227574619 Seed Coat Development and Dormancy/ links/5751b63e08ae17e65ec34208.pd

Department of Agriculture Forestry and Fisheries. 2016. Honeybush tea production guideline. DAFF, Pretoria.

Dewir, Y.H., Murthy, H.N., Ammar, M.H., et al. 2016. In vitro rooting of leguminous plants: Difficulties, alternatives, and strategies for improvement. Horticulture, Environment, and Biotechnology 57(4), 311-322. https://doi.org/10.1007/ s13580-016-0060-6.

Gutterman, Y. 2000. Maternal effects on seeds during development. In: Fenner M, editor. Seeds: The Ecology of Regeneration in Plant Communities. CABI Pub, New York, pp. 59-84. https://doi.org/10.1079/9780851994321.0059.

John, J.A., Quenouille, M.H. 1977. Experiments: Design and Analysis. 2nd Edition. Charles Griffin and Company LTD, London. 
Joubert, E., Joubert, M.E., Bester, C., De Beer, D., De Lange, J.H. 2011. Honeybush (Cyclopia spp.): from local cottage industry to global markets - the catalytic and supporting role of research. South African Journal of Botany 77(4), 887-907. https://doi.org/10.1016/j.sajb.2011.05.014.

Joubert, M., Joubert, L. 2012. Farming with honeybush - general guidelines. (Unpublished training material.) ARC Infruitec-Nietvoorbij, Stellenbosch.

Koen, J. 2015. Germination characteristics of dimorphic honeybush (Cyclopia spp.) seed. M.Tech. dissertation, Tshwane University of Technology, Pretoria.

Koen, J., Slabbert, M.M., Bester, C., Bierman, F. 2017. Germination characteristics of dimorphic honeybush (Cyclopia spp.) seed. South African Journal of Botany 110, 68-74. https://doi.org/10.1016/j.sajb.2016.03.006.

Koen, J., Slabbert, M. M., Booyse, M., Bester, C. 2020a. Honeybush (Cyclopia spp.) pollen viability and surface morphology. South African Journal of Botany, 128 167-173. https://doi.org/10.1016/j.sajb.2019.11.004.

Koen, J., Slabbert, M. M., Booyse, M., Bester, C. 2020b. Honeybush (Cyclopia spp.) anther-stigma distance and intraspecies cross compatibilities. South African Journal of Plant and Soil, 1-6. https://doi.org/10.1080/02571862.2020.1815 879.

Kokotkiewicz, A., Luczkiewicz, M., Hering, A., et al. 2012. Micropropagation of Cyclopia genistoides, an endemic South African plant of economic importance. Zeitschrift fur Naturforschung. C, Journal of biosciences 67(1-2), 65-76. Zeitschrift fur Naturforschung. C, Journal
https://doi.org/10.1515/znc-2012-1-209.

Levene, H. 1960. Robust test in the equality of variance, in: Olkin, I. (Ed.), Contributions to Probability and Statistics. Stanford University Press, Redwood City.

McGregor, G.K. 2017. Guidelines for the sustainable harvesting of wild honeybush. Department of Environmental Affairs and Development Planning, Cape Town.

Monnier, M. 2012. Culture of Zygotic Embryos, in: Thorpe, T.A. (Ed.), In Vitro Embryogenesis in Plants. Springer Science and Business Media, Dordrecht.

Motsa, M.M., Bester, C., Slabbert, M.M., Hannweg, K., Booyse, M. 2018. Flow cytometry: a quick method to determine ploidy levels in honeybush (Cyclopia spp.). Genetic Resources and Crop Evolution 65(6), 1711-1724. https://doi. spp.). Genetic Resources and Crop
org/10.1007/s10722-018-0648-z.

Motsa, M.M., Bester, C., Slabbert, M.M., Ngwenya, M.Z., Booyse, M. 2017. Natural fecundity and germination characteristics of selected Cyclopia (Honeybush) species: preliminary findings. The Journal of Agricultural Science 9(6), 154167. https://doi.org/10.5539/jas.v9n6p154.
Murashige, T., Skoog, F. 1962. A revised medium for rapid growth and bio assays with tobacco tissue cultures. Physiologia Plantarum 15(3), 473-497. https:// doi.org/10.1111/j.1399-3054.1962.tb08052.x.

Ott, R.L., Longnecker, M. 2001. An introduction to statistical methods and data analysis., fifth ed. Duxbury Press, Duxbury.

Penfield, S., MacGregor, D.R. 2016. Effects of environmental variation during seed production on seed dormancy and germination. Journal of Experimental Botany 68(4), 819-825. https://doi.org/10.1093/jxb/erw436.

Postma, F.M., Ågren, J. 2015. Maternal environment affects the genetic basis of seed dormancy in Arabidopsis thaliana. Molecular Ecology 24(4), 785-797. seed dormancy in Arabidopsis thal
https://doi.org/10.1111/mec.13061.

Pratap, A., Choudhary, A.K., Kumar, J. 2010. In vitro techniques towards genetic enhancement of food legumes - a review. Journal of Food Legumes 23(3-4), 169-185.

Sánchez-Romero, C., Perán-Quesada, R., Márquez-Martín, B., Barceló-Muñoz, A., Pliego-Alfaro, F. 2007. In vitro rescue of immature avocado (Persea americana Mill.) embryos. Scientia Horticulturae 111(4), 365-370. https://doi. org/10.1016/j.scienta.2006.11.009.

Schutte, A.L. 1997. Systematics of the genus Cyclopia Vent. (Fabaceae, Podalyrieae). Edinburgh Journal of Botany 54(2), 126-133. https://doi.org/10.1017/ S0960428600004005.

Shapiro, S.S., Wilk, M.B. 1965. An analysis of variance test for normality (complete samples). Biometrika 52(3-4), 591-611. https://doi.org/10.1093/ biomet/52.3-4.591.

Smith, R.H. 2012. Plant tissue culture: techniques and experiments. Academic Press, Massachusetts.

Wang, Z., Luo, Y., Li, X., et al. 2008. Genetic control of floral zygomorphy in pea (Pisum sativum L.). Proceedings of the National Academy of Sciences 105(30), 10414-10419. https://doi.org/10.1073/pnas.0803291105.

Whitehead, C.S., Sutcliffe, M. 1995. Effect of low temperatures and different growth regulators on seed germination in Cyclopia spp. The Journal of Plant Physiology 147(1), 107-112. https://doi.org/10.1016/S0176-1617(11)81421-5.

Wooldridge, J., Joubert, M., Booyse, M. 2012. Comparison between the Honeybush species Cyclopia genistoides and C. subternata. SA Fruit Journal 11(5), 46-47.

Wulff, R.D. 2017. Environmental maternal effects on seed quality and germination, in: Kigel, J. (Ed.), Seed Development and Germination. CRC Press, New York. https://doi.org/10.1201/9780203740071-18. 